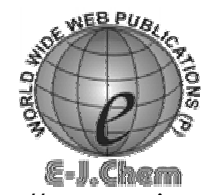

http://www.e-journals.net
ISSN: 0973-4945; CODEN ECJHAO

E-Journal of Chemistry

Vol. 1, No. 1, pp 43-50, March 2004

\title{
Comparative Bioavailability of Four Marketed Sparfloxacin Formulations in Healthy Human Volunteers
}

\author{
K. RAVINDRA RAO, J. VIJAYA RATNA* and T. MANIKYA RAO \\ Department of Pharmaceutical Sciences \\ Andhra University, Visakhapatnam- 530 003, India. \\ vijaya_ratna@yahoo.com
}

Received 10 February 2004; Accepted 24 February 2004

\begin{abstract}
The objective of the study was to obtain the pharmacokinetic data of four marketed tablet formulations of sparfloxacin and compare the relative bioavailability of the formulations with standard formulation. A single dose $4 \times 4$ latin square design of the four marketed tablet formulations of sparfloxacin (200 $\mathrm{mg}$ ) was carried out in four healthy male volunteers. Blood samples were collected at predetermined time intervals. The serum concentrations of the drug were determined by microbiological assay. The pharmacokinetic parameters were calculated from the plasma concentration of sparfloxacin versus time data. The $\mathrm{AUC}_{0-\alpha}$ of the sparfloxacin from products $\mathrm{A}, \mathrm{B}, \mathrm{C}$ and $\mathrm{D}$ was $23.33 \pm 3.90 \mu \mathrm{g}$ $\mathrm{h} / \mathrm{mL}, 19.72 \pm 2.47 \mu \mathrm{g} \mathrm{h} / \mathrm{mL}, 18.76 \pm 5.19 \mu \mathrm{g} \mathrm{h} / \mathrm{mL}$ and $18.27 \pm 2.84 \mu \mathrm{g} \mathrm{h} / \mathrm{mL}$ respectively. The $\mathrm{C}_{\max }$ and $\mathrm{t}_{1 / 2}$ of the sparfloxacin was $0.98 \pm 0.07 \mu \mathrm{g} / \mathrm{mL}, 14.91$ $\pm 1.30 \mathrm{~h}, 0.80 \pm 0.06 \mu \mathrm{g} / \mathrm{mL}, 15.75 \pm 2.37 \mathrm{~h}, 0.78 \pm 0.11 \mu \mathrm{g} / \mathrm{mL}, 16.01 \pm 1.98$ and $0.81 \pm 0.04 \mu \mathrm{g} / \mathrm{mL}, 13.91 \pm 3.59 \mathrm{~h}$ respectively for the products $\mathrm{A}, \mathrm{B}, \mathrm{C}$ and D. The serum concentration of the sparfloxacin and other pharmacokinetic parameters obtained were statistically analyzed. The results of three-way analysis of variance of serum drug levels and pharmacokinetic parameters showed that there was no significant variation between the products, subjects and treatments at all the points of time with regard to the $\mathrm{AUC}_{0-\alpha}, \mathrm{C}_{\max }$ and $\mathrm{t}_{1 / 2}$. The results of the study indicated that the products $\mathrm{A}, \mathrm{B}, \mathrm{C}$ and $\mathrm{D}$ are bioequivalent.
\end{abstract}

Keywords: Bioavailability; Sparfloxacin; Human volunteers; Pharmacokinetics

\section{Introduction}

Systemic drugs administered orally or parenterally must reach the general circulation in their pharmacologically active form to be distributed throughout the body and to exert therapeutic effect. The intensity of the therapeutic actions of the many drugs is correlated well with the concentrations of the drugs in the biological fluid ${ }^{1}$. The rate of absorption is therapeutically important with single doses of drugs, where relatively small changes in the concentration can lead to marked changes in pharmacodynamic reponse. 
Sparfloxacin is an aminofluroquinolone derivative. ${ }^{2,3}$ It has broad spectrum of activity against gram positive and gram negative organisms. It is structurally 5-amino-1cyclopropyl-7-(cis-3,5-dimethyl)-1-piperozinyl)-6,8-difluoro-1,4-dihydro-4-oxo-3- uinoline. Sparfloxacin is $45 \%$ bound to serum proteins and has a half life of $20 \pm 4 \mathrm{~h}^{4}{ }^{4}$ Sparfloxacin allows for once daily dosage regimen. Tablets containing sparfloxacin equivalent to $200 \mathrm{mg}$ of sparfloxacin are available in the market. It is used in the treatment of respiratory tract infections, tuberculosis and diabetic foot infections ${ }^{4}$. It has excellent bioavailability $(92 \%)$ compared to other fluroquinolone derivatives. ${ }^{5}$ It has exceptional volume of distribution ranging from 4.5 to $5.5 \mathrm{~L} / \mathrm{kg}$. After a single oral dose, only 10 to $14 \%$ of sparfloxacin was recovered in the urine unchanged. Sparfloxacin and moxifloxacin have relatively prolonged $\mathrm{t}_{1 / 2}$ ranging from 15 to $24 \mathrm{~h}$ and 9 to $15 \mathrm{~h}$ respectively following single oral doses. ${ }^{6}$

Most of the bioequivalence studies on which the claims of bioequivalence to innovator product do not use confidence interval (CI ). Determination of CI is a current regulatory requirement of Drug Controller General of India and also of FDA (www. Fda.gov/gov/cder/guidance/index.htm) to document bioequivalance. Thus, the only way to verify these claims is to do a comparative bioequivalance study with the innovator drug formulation.

Bioequivalance studies of different formulations of sparfloxacin are useful because of its special pharmacokinetic nature. A small change in the concentration can lead to marked changes in pharmacodynamic reponse. Hence, the present study was carried out to compare the bioavailability of four brands of $200 \mathrm{mg}$ sparfloxacin in healthy, adult, male, human volunteers under fasted conditions.

\section{Experimental}

Pure sparfloxacin was obtained from M/s. Dr. Reddy's Laboratories, Hyderabad. Nutrient Agar Hi-media was procured from Hi-media Laboratories Ltd., Mumbai. Sodium lauryl sulphate (SLS) and methanol were purchased from M/s. Qualigens Fine Chemicals, Mumbai, India. Four marketed tablet formulations of sparfloxacin $200 \mathrm{mg}$ each; Torospar (Torrent Pharmaceutical Ltd.), Flospar (Unichem Laboratories Ltd.), Sparta (Alembic Pharmaceutical Ltd.) and Sparquin (Aristo Pharmaceutical Ltd.) were selected for the study.

\section{$U V$-Spectrophotometric estimation of sparfloxacin in tablets and dissolution fluids}

The quantitative determination sparfloxacin was estimated by an UV-Spectrophotometric method $^{7}$. The absorbance of the dissolution samples was measured by UV-150-02 Spectrophotometer (Elico India Ltd.) at $304 \mathrm{~nm}$ using water containing $0.5 \%$ SLS as blank. The method was validated for linearity, accuracy and precision. The method obeys Beer's law in a concentration range $2-10 \mu \mathrm{g} / \mathrm{mL}$ when this standard drug solution was assayed repeatedly $(\mathrm{n}=6)$ the mean error (accuracy) and relative standard deviation (precision) were found to be $0.6 \%$ and $1.0 \%$ respectively.

\section{Quantitative determination of drug content in sparfloxacin tablets}

Four marketed tablet formulations of sparfloxacin tablets were tested for their drug content. Five tablets of either of the formulation were finely powdered. The powder equivalent to $25 \mathrm{mg}$ of sparfloxacin was accurately weighed and transferred to $100 \mathrm{~mL}$ volumetric flask containing $50 \mathrm{~mL}$ of methanol and allowed to stand for $6 \mathrm{~h}$ with intermittent sonication to ensure complete solubility of the drug. Then the volume was made up to $100 \mathrm{~mL}$ with methanol, the mixture was centrifuged, $1 \mathrm{~mL}$ of the supernatant liquid was suitably diluted 
withmethanol, filtered, and analyzed for sparfloxacin by UV-Spectrophotometric method as described above.

\section{In vitro drug release studies}

The in vitro drug release studies of sparfloxacin tablets were carried out using a three basket USP XXIII Dissolution Rate Test Apparatus (Apparatus 1, $50 \mathrm{rpm}, 37 \pm 0.5^{\circ} \mathrm{C}$ ). The tablets were tested for drug release for $2 \mathrm{~h}$ in distilled water containing $0.5 \%$ SLS (900 mL) as the average gastric emptying time is about $2 \mathrm{~h}$. The samples $(5 \mathrm{~mL})$ were withdrawn through filter at different time intervals $(15,30,45,60,90$ and $120 \mathrm{~min})$ and were analyzed at 304 $\mathrm{nm}$ for sparfloxacin using double beam spectrophotometer (Elico India Ltd.).

\section{In- vivo evaluation in healthy volunteers}

The Institutional Ethical Committee (Andhra University) approved the protocol of the study involving the pharmacokinetic evaluation of sparfloxacin tablets. All the volunteers were explained the full details of the possible side effects of the drug formulation and were given freedom to withdraw from the study as and when they feel for such a need. The informed written consent was obtained from every volunteer who had participated in the study.

Four healthy male volunteers participated in the study. All the volunteers were in the age group of 21-24 years (weight ranging from $55 \mathrm{~kg}$ to $60 \mathrm{~kg}$ ). All the volunteers were subjected for physical, biochemical and pathological examination to ascertain that they are healthy. The concurrent use of other drugs, alcoholic beverages and smoking was restricted one week prior to the study and were prohibited during the study ${ }^{8}$.

\section{Bioequivalence study protocol}

The protocol on the study days was the same on each occasion. At about 8 a.m. on each day, subjects received according to a randomized $4 \times 4$ latin square design a tablet of sparfloxacin such that each volunteer received four different formulations on four separate occasions with a washout period of one week. The volunteers were fasted over night before the drug administration and for $4 \mathrm{~h}$ after drug administration ${ }^{9}$. Blood samples were collected at $0.5,1,1.5$, $2,3,4,5,6,7,12,18,24,30,36$ and $48 \mathrm{~h}$ post dosing by using a $22 \mathrm{G}^{\prime \prime}(0.9 \times 25 \mathrm{~mm})$ i.v. canula with injection port positioned in the forearm vein and was kept with non-heparinised centrifuge tubes. Blood samples were immediately centrifuged and serum was transferred into $5 \mathrm{~mL}$ vials, capped tightly and stored at $-40^{\circ} \mathrm{C}$ until analysis by a sensitive microbiological assay method.

\section{Microbiological assay of sparfloxacin in human serum}

A cup-plate method was used for the estimation of sparfloxacin in serum samples. Standard serum concentrations ranging from 0.1 to $0.9 \mu \mathrm{g} / \mathrm{mL}$ were obtained by suitably diluting the stock solution (100 mg of sparfloxacin in $100 \mathrm{~mL}$ of distilled water) with antibiotic free serum. The medium was distributed in to boiling tubes, which were then cooled to $40^{\circ} \mathrm{C}$ and inoculated with $0.05 \mathrm{~mL}$ of cell suspension (Bacillus subtilis). The inoculated medium was then mixed and poured into sterile assay plates. The plates were allowed to remain on a flat surface for $1 \mathrm{~h}$ to solidify. A sterile cork borer was used to make 5 cups in each plate. The drug solution $(50 \mu \mathrm{L})$ was placed in each cup. Each concentration was repeated four times. This standard graph was used for the determination of serum sparfloxacin in in vivo studies. The method was developed based on established method in the determination of sparfloxacin in serum and urine by high performance liquid chromatography for validation of HPLC method ${ }^{10}$. 


\section{Drug analysis and calculation of pharmacokinetic parameters}

The serum concentration of sparfloxacin at different time intervals was subjected to pharmacokinetic analysis to calculate various parameters such as maximum plasma concentration $\left(\mathrm{C}_{\max }\right)$, time to reach maximum concentration $\left(\mathrm{T}_{\max }\right)$ and area under the curve $\left(\mathrm{AUC}_{0-\infty}\right.$ ). The values of $\mathrm{C}_{\max }$ and $\mathrm{T}_{\max }$ were directly read from the arithmetic plot of time versus plasma concentration of sparfloxacin. The overall elimination rate constant $\left(\mathrm{k}_{\mathrm{e}}\right)$ was calculated from the slope of the terminal elimination phase of a semi-log plot of concentration versus time, after subjecting it to linear regression analysis. Assuming the elimination to be a first-order process:

$$
\mathrm{t}_{1 / 2}=0.693 / \mathrm{k}_{\mathrm{e}} \text { where } \mathrm{k}_{\mathrm{e}}=\text {-slope } * 2.303
$$

The area under the curve of time versus plasma concentration of sparfloxacin $\left(\mathrm{AUC}_{0-\propto}\right)$ was calculated by using trapezoidal rule. Initially $\mathrm{AUC}_{0-\mathrm{t}}$ was calculated using trapezoidal rule and $\mathrm{AUC}_{0-\infty}$ was obtained using the following equation.

$$
\mathrm{AUC}_{0-\infty}=\mathrm{AUC}_{0-\mathrm{t}}+\mathrm{c} / \mathrm{k}_{\mathrm{e}}
$$

where ' $c$ ' is the plasma concentration of sparfloxacin at the last time-point ' $\mathrm{t}$ '.

\section{Statistical Analysis}

Typical descriptive analysis [mean, standard deviation(s) or standard error $\left(\mathrm{s}_{\overline{\mathrm{x}}}\right)$ and coefficient of variation (CV)] was applied to the data collected in this study. Comparison of the standard pharmcokinetic measures obtained was carried out using three way analysis of variance (ANOVA). Subject, treatment, and time effect were accounted for values of $\mathrm{P}<$ 0.05 and were taken to indicate statistically significant differences ${ }^{11}$.

\section{Results and Discussion}

The selected formulations of sparfloxacin were tested for hardness, drug content and were subjected to in vitro drug release studies. All the four marketed tablet formulations tablets satisfied the drug content as they contained $99.0 \%$ to $99.18 \%$ of drug indicating the uniformity of the drug content. The mean values for hardness of sparfloxacin tablets were in the range of $3.5 \pm 0.07$ to $4.5 \pm 0.08 \mathrm{~kg} / \mathrm{cm}^{2}$. The hardness values of all brands are well with in the acceptable limits. The disintegration times of the four brands ranged from $2.16 \pm 0.01$ to $3.66 \pm 0.05 \mathrm{~min}$. and fulfilled disintegration limits.

The percent of drug released at different time intervals from the sparfloxacin tablets were given in Table 1 . The mean percent of drug released from sparfloxacin tablets was found to be $96.5 \%$ to $98.9 \%$ at end of $2 \mathrm{~h}$ of testing in distilled water containing $0.5 \%$ SLS $(900 \mathrm{~mL})$. The SLS was used in the dissolution medium to provide sink condition. From the dissolution profiles, it was observed that all brands of sparfloxacin was released gradually almost $100 \%$ in $2 \mathrm{~h}$ Table 1 . Sparfloxacin release from the tablets followed first order release rate constant. The correlation coefficient (r) between $\log$ percent remaining and time was in the range $0.976 \pm 0.005$ to $0.993 \pm 0.003$ for all brands. Analysis of variance (ANOVA) test was done for $\mathrm{k}_{1}$ values obtained. The $F$-ratio obtained is less than the table values, which shows that there is no significant difference among $\mathrm{k}_{1}$ values obtained. 
Table 1. *Mean ( \pm s.d.) release characteristics of four marketed formulations of sparfloxacin.

\begin{tabular}{cccccc}
\hline \multirow{2}{*}{ Parameters } & \multicolumn{4}{c}{ Products } \\
\cline { 3 - 6 } & & $\mathrm{A}$ & $\mathrm{B}$ & $\mathrm{C}$ & $\mathrm{D}$ \\
\hline Average & 15 & $50.56 \pm 1.19$ & $25.10 \pm 3.58$ & $25.79 \pm 2.86$ & $32.83 \pm 1.86$ \\
& 30 & $74.76 \pm 4.75$ & $46.24 \pm 3.48$ & $49.08 \pm 4.28$ & $59.08 \pm 2.25$ \\
percent drug & 45 & $85.90 \pm 3.87$ & $71.81 \pm 3.55$ & $69.19 \pm 4.10$ & $75.10 \pm 2.41$ \\
released at 6 & 60 & $91.58 \pm 1.90$ & $79.54 \pm 2.49$ & $79.99 \pm 3.94$ & $88.51 \pm 1.50$ \\
& 90 & $97.83 \pm 2.83$ & $89.65 \pm 3.72$ & $92.49 \pm 2.17$ & $96.47 \pm 1.59$ \\
time points(h) & 120 & $98.85 \pm 1.20$ & $93.85 \pm 2.98$ & $96.47 \pm 2.20$ & $98.97 \pm 1.45$ \\
$\mathrm{k}_{1}\left(\mathrm{~h}^{-1}\right)$ & & $0.0459 \pm 0.02$ & $0.027 \pm 0.00$ & $0.0302 \pm 0.00$ & $0.0508 \pm$ \\
$\mathrm{t}_{50}(\mathrm{~h})$ & & $16.80 \pm 2.1$ & $27.39 \pm 3.08$ & $23.37 \pm 3.78$ & $14.96 \pm 4.21$ \\
\hline
\end{tabular}

$\mathrm{t}_{50}$ is time for $50 \%$ release, $\mathrm{k}_{1}$ is dissolution rate constant SD stands for standard deviation.

*Mean of three experiments

Dissolution efficiency $\left(\mathrm{DE}_{30}\right)$ values were calculated from the dissolution data as suggested by Khan ${ }^{12}$. The dissolution efficiency for all four brands ranged from $23.33 \pm$ 1.55 to $45.41 \pm 1.26$, in dissolution medium of water containing $0.5 \%$ SLS. It was found that percent dissolved of all four brands in pure distilled water was very poor, that is less than $25 \%$ at the end of $2 \mathrm{~h}$. Hence SLS was added to the dissolution medium, which increases in dissolution efficiency for all 4 brands.

The pharmacokinetic parameters $\mathrm{T}_{\max }$ and $\mathrm{AUC}_{0-\alpha}$, are related to the rate and extent of absorption respectively, while $\mathrm{C}_{\max }$ is related to both the process ${ }^{13}$. The extent of absorption is a key characteristic of a drug formulation, and therefore the $\mathrm{AUC}_{0-\alpha}$ is an important parameter for analysis in a comparative bioavailability study. However, the other two parameters, namely $\mathrm{T}_{\max }$ and $\mathrm{C}_{\max }$, are also important features of the plasma level profile that are related to the therapeutic use of many $\operatorname{drugs}^{14}$ and hence are also considered in the present pharmacokinetic analysis.

Latin Square Design, a very efficient design is used for in vivo bioequivalency studies. The study periods are taken as rows subjects are taken as columns and formulations are taken as different treatments. Sparfloxacin was administered at a dose of $200 \mathrm{mg}$ tablets. There were no significant protocol deviations and all the 12 subjects completed the study. The mean serum levels of sparfloxacin levels obtained following administration of product $\mathrm{A}, \mathrm{B}, \mathrm{C}$ and $\mathrm{D}$ manufactured by different pharmaceutical companies were shown in Figure 1. On oral administration of sparfloxacin tablets (products $\mathrm{A}, \mathrm{B}, \mathrm{C}$ and $\mathrm{D}$ ), the drug appeared in plasma with in $0.5 \mathrm{~h}$ and produced peak plasma concentration $\left(\mathrm{C}_{\max }\right)$ of $0.98 \pm 0.07,0.80 \pm 0.06,0.78 \pm 0.11$ and $0.81 \pm 0.04$ at around $5 \mathrm{~h}\left(\mathrm{~T}_{\max }\right)$. The mean elimination half-life $\left(\mathrm{t}_{1 / 2}\right)$ for sparfloxacin following oral ingestion of products $\mathrm{A}, \mathrm{B}, \mathrm{C}$ and $\mathrm{D}$ were $14.91 \pm 1.30,15.75 \pm 2.37,16.01 \pm 1.98$ and $13.91 \pm .59$ respectively which were not significantly different from each other $(\mathrm{P}>0.05)$. These values are in good agreement with the reported $t_{1 / 2}$ ranged from 16 to $22 h^{4,6}$. The good agreement of $t_{1 / 2}$ estimated in the present work by the microbiological assay method with the reported values indicated that the suitability of microbiological method of estimation of serum sparfloxacin for pharmacokinetics. 


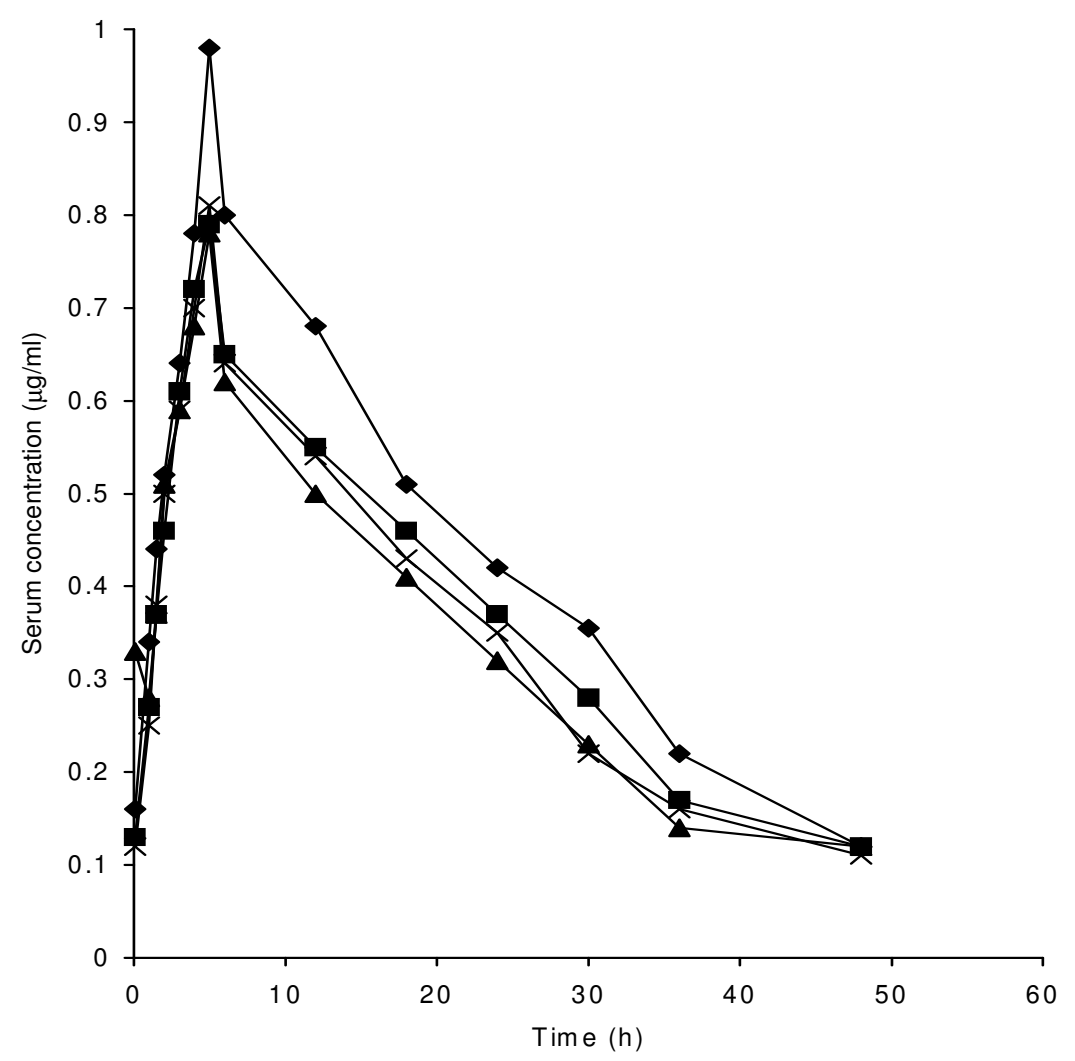

Figure 1. Mean serum concentration with time profile of sparfloxacin in human volunteers $(n=4)$.

\section{Legends for figure}

Mean serum concentrations $(\mu \mathrm{g} / \mathrm{mL})$ of sparfloxacin $(\mathrm{n}=4)$ at difference time intervals following administration of four marketed tablet formulations. Formulation A (Torospar,-), formulation B (Flospar,- -), formulation C (Sparta,-- -) and formulation D (Sparquin, -X-) each containing $200 \mathrm{mg}$ of sparfloxacin.

The area under plasma sparfloxacin concentration versus time curve $\left(\mathrm{AUC}_{0-\alpha}\right)$ for the products $\mathrm{A}, \mathrm{B}, \mathrm{C}$ and $\mathrm{D}$ were ranged $23.33 \pm 3.90 \mu \mathrm{g} \mathrm{h} / \mathrm{mL}, 19.72 \pm 2.47 \mu \mathrm{g} \mathrm{h} / \mathrm{mL}, 18.76 \pm 5.19$ $\mu \mathrm{g} \mathrm{h} / \mathrm{mL}$ and $18.27 \pm 2.84 \mu \mathrm{g} \mathrm{h} / \mathrm{mL}$ respectively, and were not significantly different ( $\mathrm{P}>0.05$ ) from each other. The mean residence time (MRT) of 4 tablet formulations A, B, $\mathrm{C}$ and $\mathrm{D}$ ranged from $20.5 \pm 0.99$ to $22.57 \pm 2.46 \mathrm{~h}$. The results indicate a significant difference between formulations but no significant difference between study periods and subjects. The values of pharmacokinetic parameters $\left(\mathrm{AUC}_{0-\alpha}, \mathrm{C}_{\max }, \mathrm{T}_{\max }\right.$ or $\mathrm{t}_{1 / 2}$ ) obtained in the present study are in good agreement with reported values ${ }^{4,6}$. The good agreement of estimated pharmacokinetic parameters in the present work by the microbiological assay method with the reported values indicated that the suitability of microbiological method of estimation of serum sparfloxacin for pharmacokinetics. Thus, the results indicate that similar drug absorption rate for all drug products (Table 2). 
Table 2. Mean ( \pm s.d.) pharmacokinetic parameters of sparfloxacin in human volunteers $(n=4)$ following oral administration (dose $200 \mathrm{mg}$ ) of four marketed formulations under the fasted conditions.

\begin{tabular}{|c|c|c|c|c|}
\hline \multirow{2}{*}{ Parameters } & \multicolumn{4}{|c|}{ Products } \\
\hline & A & B & $\mathrm{C}$ & D \\
\hline $\mathrm{C}_{\max }(\mu \mathrm{g} / \mathrm{mL})$ & $0.98 \pm 0.07$ & $0.80 \pm 0.06$ & $0.78 \pm 0.11$ & $0.81 \pm 0.04$ \\
\hline$t_{\max }(h)$ & 5 & 5 & 5 & 5 \\
\hline $\mathrm{t}_{1 / 2}(\mathrm{~h})$ & $14.91 \pm 1.30$ & $15.75 \pm 2.37$ & $16.01 \pm 1.98$ & $13.91 \pm 3.59$ \\
\hline $\mathrm{AUC}_{0-\alpha}(\mu \mathrm{g} \mathrm{h} / \mathrm{mL})$ & $23.33 \pm 3.90$ & $19.72 \pm 2.47$ & $18.76 \pm 5.19$ & $18.27 \pm 2.84$ \\
\hline $\operatorname{MRT}(\mathrm{h})$ & $20.50 \pm 0.99$ & $22.57 \pm 2.46$ & $21.65 \pm 1.93$ & $2.082 \pm 1.68$ \\
\hline $\begin{array}{l}\text { Average } \% \text { drug } \\
\text { absorbed after } 2 \mathrm{~h}\end{array}$ & $53.20 \pm 9.86$ & $54.53 \pm 6.46$ & $66.15 \pm 8.81$ & $55.28 \pm 9.59$ \\
\hline $\begin{array}{l}\text { Relative } \\
\text { Bioavailability }\end{array}$ & 100 & 84.52 & 80.41 & 78.3 \\
\hline
\end{tabular}

$t_{1 / 2}$ is half life and SD stands for standard deviation.

The results of ANOVA test done on various pharmaceokinetic parameters are shown in Table 3. It is observed that except in one case (\% absorbed at $2 \mathrm{~h})$ there is no significant difference in any pharmacokinetic parameter among the different subjects. Similarly except in two cases (AUC and $\mathrm{k}_{\mathrm{a}}$ ) there is no significant difference regarding any parameter among the different study periods. Coming to the treatments difference is significant in the case of four parameters (AUC, $\mathrm{C}_{\max }, \mathrm{k}_{\mathrm{a}}$ and percent absorbed at $2 \mathrm{~h}$ ) but not significant in the case of two parameters $\left(t_{\max }\right.$ and $\left.k_{e l}\right)$ studied. It is concluded that there is no inter subject variability and there is no time effect on various study periods.

The results suggest bioinequivalence among treatments but it should be verified whether the bioinequivalence is of practical significance by doing percent relative bioavailability test. The product A that has given maximum bioavailability is taken as reference standard. The relative bioavailability of sparfloxacin formulations B, C and D was calculated by dividing its AUC with that of formulation A (reference formulation). As per FDA guidelines if the percent relative bioavailability falls between 80 to $120 \%$ of the reference, the products are considered as bioequivalent. In the present study, the bioavailability of the test products $\mathrm{B}, \mathrm{C}$ and $\mathrm{D}$ was $84.52 \%, 80.41 \%$ and $78.3 \%$ with respect to reference. The relative bioavailability of product $\mathrm{D}$ is very narrowly $(78.3 \%)$ less than the practical limit. However the narrow difference is not significant and it may be concluded that products of sparfloxacin marketed by different pharmaceutical companies are bioequivalent (Table 2).

Table 3. Three way ANOVA comparison of serum levels and pharmacokinetic parameters of sparfloxacin formulations.

\begin{tabular}{ccccccc}
\hline \multirow{2}{*}{ Parameters } & \multicolumn{2}{c}{ Treatments } & \multicolumn{2}{c}{ Subjects } & \multicolumn{2}{c}{ Time effect } \\
\cline { 2 - 7 } & F value & F value & F value & \\
\hline AUC $(\mu \mathrm{g} \mathrm{h} / \mathrm{mL})$ & 5.28 & $\mathrm{~S}$ & 0.189 & $\mathrm{NS}$ & 12.09 & $\mathrm{~S}$ \\
$\mathrm{C}_{\max }(\mu \mathrm{g} / \mathrm{mL})$ & 7.2 & $\mathrm{~S}$ & 0.66 & $\mathrm{NS}$ & 1.32 & $\mathrm{NS}$ \\
$\mathrm{t}_{\max }(\mathrm{h})$ & -- & $\mathrm{NS}$ & -- & $\mathrm{NS}$ & -- & $\mathrm{NS}$ \\
$\mathrm{K}_{\mathrm{a}}\left(\mathrm{h}^{-1}\right)$ & 11.01 & $\mathrm{~S}$ & 2.5 & $\mathrm{NS}$ & 10.31 & $\mathrm{~S}$ \\
$\mathrm{~K}_{\mathrm{el}}\left(\mathrm{h}^{-1}\right)$ & 2.48 & $\mathrm{NS}$ & 1.99 & $\mathrm{NS}$ & 4.12 & $\mathrm{NS}$ \\
$\%$ Absorbed at $2 \mathrm{~h}$ & 5.59 & $\mathrm{~S}$ & 5.53 & $\mathrm{~S}$ & 2.61 & $\mathrm{NS}$ \\
\hline
\end{tabular}

F value at 3,6 , d.f at $5 \%$ probability level is $4.76 \mathrm{NS}$ stands for statistically not significant while $\mathrm{S}$ stands for statistically significant at $\mathrm{p}<0.05$-- stands for all $\mathrm{t}_{\max }$ values similar $(5 \mathrm{~h})$ 


\section{Conclusions}

The present study was carried out to obtain the pharmacokinetic data of four marketed tablet formulations of sparfloxacin and compare the relative bioavailability of the formulations with standard formulation. From the dissolution profiles, it was observed that all brands of sparfloxacin was released gradually almost $100 \%$ in $2 \mathrm{~h}$. It can be concluded that all the products are equivalent regarding the in vitro drug release profile. The in vivo studies of sparfloxacin products in human volunteers showed statistically significant difference regarding 3 out of 6 pharmacokinetic parameters but when \% bioavailability was tested it was found that product $\mathrm{D}$ fell very narrowly below the cut off point of bioequivalence. However the narrow difference is not significant and it may be concluded that products of sparfloxacin marketed by different pharmaceutical companies are bioequivalent. The statistical in equivalence seen at $5 \%$ probability is not of clinical significance.

\section{Acknowledgements}

Authors wish to thank Dr. Reddy's Laboratories, Hyderabad for providing the gift sample of sparfloxacin for the study and Prof. P. Ellaiah for providing lab facilities for microbiology work.

\section{References}

1. Koch-wesser, J. N Engl J of Med, 1982, 287, 227

2. Budavari S, Edn., In; The Merck Index; 12th Ed.; Merck and Co. Inc., While House Station, NJ, 1993, 1492.

3. Martindale, The Extra Pharmacopeia; 30th Ed.; The pharmaceutical press, London, 1993, 202.

4. Sakashita S, Yokogawa M and Yamaguchi, T. Xehobiotic Metab Disp, 1991, 6, 43.

5. Montay G, J Antimicrob Chemother, 1996, 37, 27.

6. Talukdar M M and Kinget R Int. J Pharm, 1995, 120, 63.

7. Chowdary K P R and Divakar M Int. Pharm Excip, 1999, 1 (4), 132.

8. The United States Pharmacopeia, 23rd Edn., The United States Pharmacopeial convention, Inc., Rockvilley, M.D. 1995, 1690.

9. Brahmankar D M, Ed.; Biopharmaceutics and pharmacokinetics, A treatise, Vallabh Prakashan, 1998, 274.

10. Borner K and Borner E J Chromatogr, 1992, 579, 285.

11. SPSS for windows, SPSS Inc., Chicago, Ib, 1994.

12. Khan K A, J Pharm Pharmacol, 1975, 27, 48.

13. Grahnen A, Design of bioavailability studies. Pharm Int, 1984 5, 100.

14. Westlake, W. J. In Biopharmaceutical statistics for drug Development (K.E. Peace, ed.), Marcel Dekker, New York, 1988, 329. 


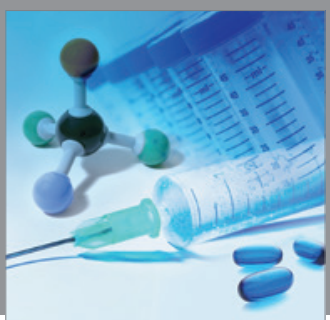

International Journal of

Medicinal Chemistry

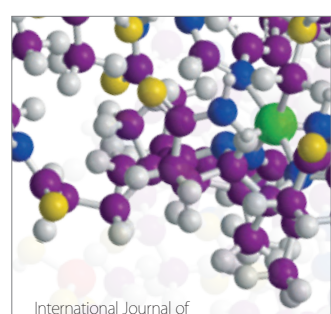

Carbohydrate Chemistry

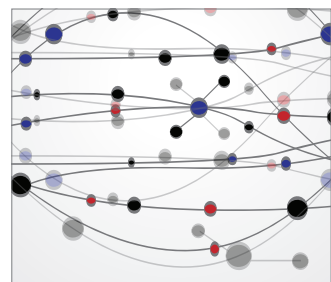

The Scientific World Journal
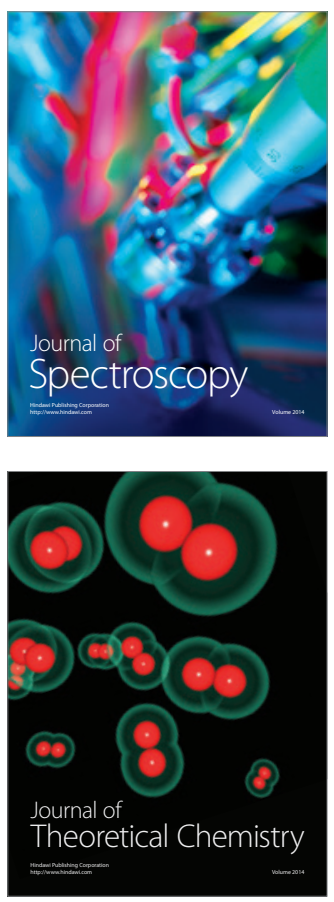
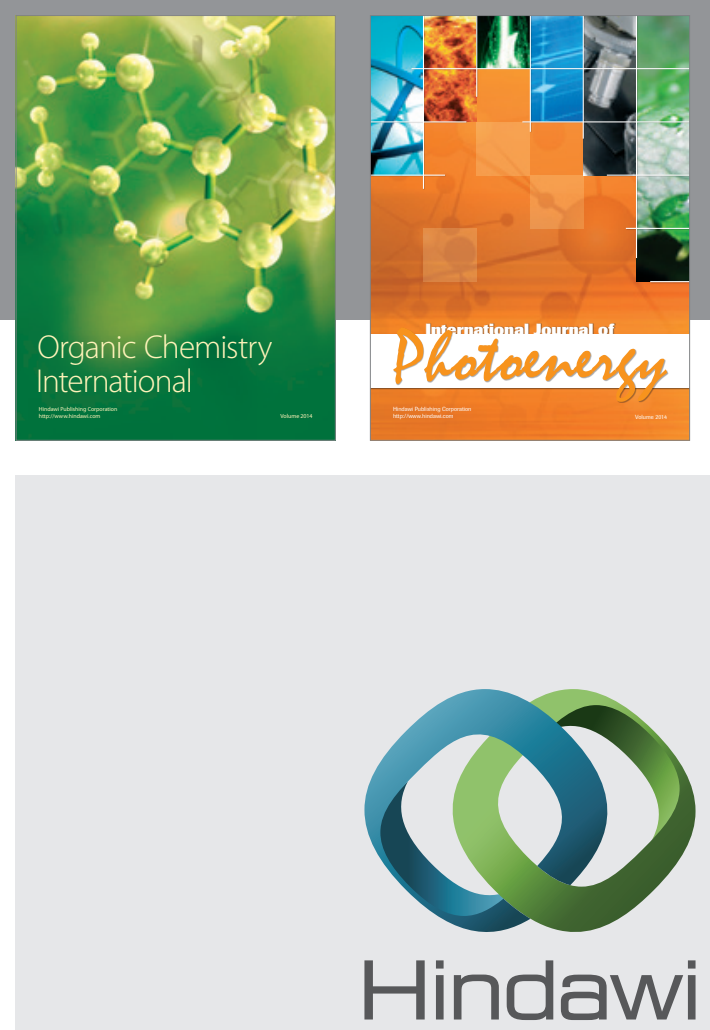

Submit your manuscripts at

http://www.hindawi.com
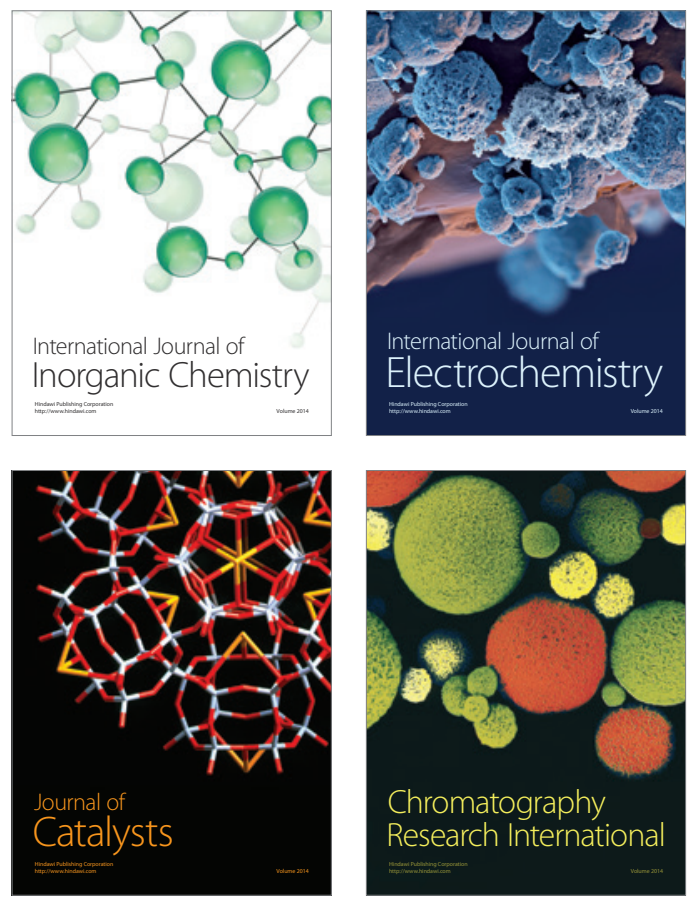
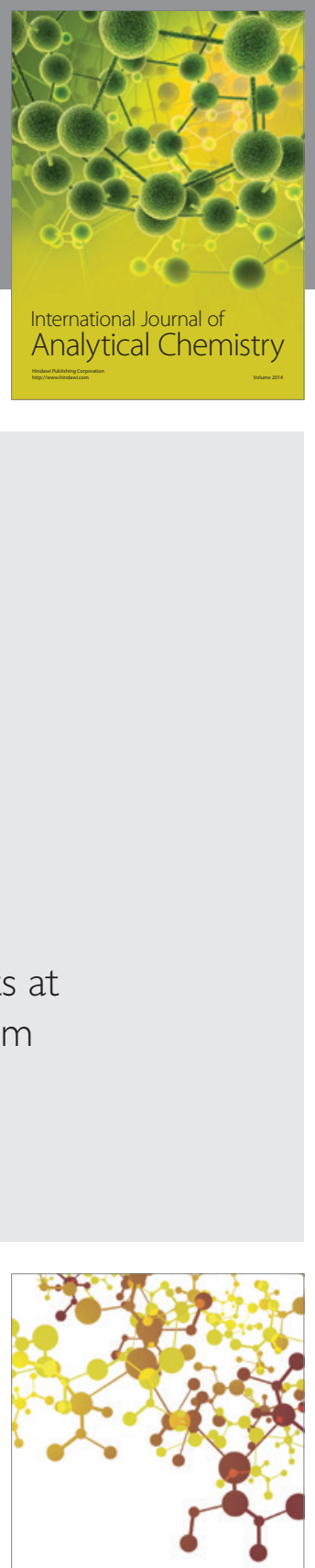

Journal of

Applied Chemistry
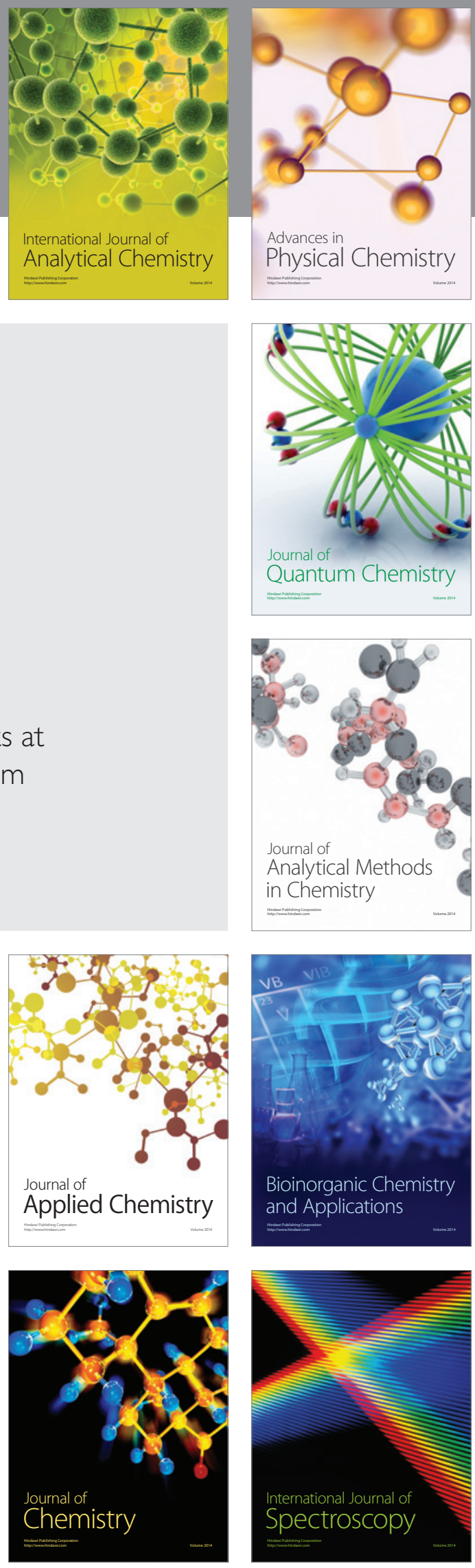